\title{
Intrapleural interleukin-2-expressing oncolytic virotherapy enhances acute antitumor effects and T-cell receptor diversity in malignant pleural disease
}

Chigozirim N. Ekeke, MD, ${ }^{\text {a }}$ Kira L. Russell, BS, ${ }^{\mathrm{b}}$ Pranav Murthy, BS, ${ }^{\mathrm{b}}$ Zong Sheng Guo, PhD, ${ }^{\mathrm{b}}$ Adam C. Soloff, PhD, ${ }^{a}$ Daniel Weber, BS, ${ }^{c}$ Wenjing Pan, PhD,${ }^{c}$ Michael T. Lotze, MD, ${ }^{\text {b,de,f }}$ and Rajeev Dhupar, MD, MBA ${ }^{\mathrm{a}, \mathrm{g}}$

\section{ABSTRACT}

Objective: The mainstay of treatment for patients with malignant pleural disease is fluid drainage and systemic therapy. A tumor-specific oncolytic virus or T-cell-activating interleukin-2 immunotherapy may provide an opportunity for local control. We previously developed a vaccinia virus-expressing interleukin-2, an oncolytic virus that mediated tumor regression in preclinical peritoneal tumor models with expansion of tumor-infiltrating lymphocytes. We evaluated the antitumor efficacy and immune modulatory effects of vaccinia virus-expressing interleukin-2 in malignant pleural disease.

Methods: A murine model of malignant pleural disease was established with percutaneous intrapleural deposition of the Lewis lung carcinoma cell line and monitored with bioluminescent imaging. After intrapleural or systemic administration of vaccinia viruses (vaccinia virus yellow fluorescent protein control, vaccinia virus-expressing interleukin-2), systemic anti-programmed cell death-1 antibody, or combination therapy (vaccinia virus-expressing interleukin-2 and anti-programmed cell death-1), tumor mass, immune cell infiltration, T-cell receptor diversity, and survival were assessed.

Results: Intrapleural vaccinia virus resulted in significant tumor regression compared with phosphate-buffered saline control $(P<.05)$. Inclusion of the interleukin-2 transgene further increased intratumoral $\mathrm{CD}^{+}$T cells $(P<.01)$ and programmed cell death-1 expression on $\mathrm{CD}^{+}$tumor-infiltrating lymphocytes $(P<.001)$. Intrapleural vaccinia virus-expressing interleukin-2 was superior to systemic vaccinia virus-expressing interleukin-2, with reduced tumor burden $(P<.0001)$ and improved survival $(P<.05)$. Intrapleural vaccinia virus-expressing interleukin-2 alone or combined treatment with systemic

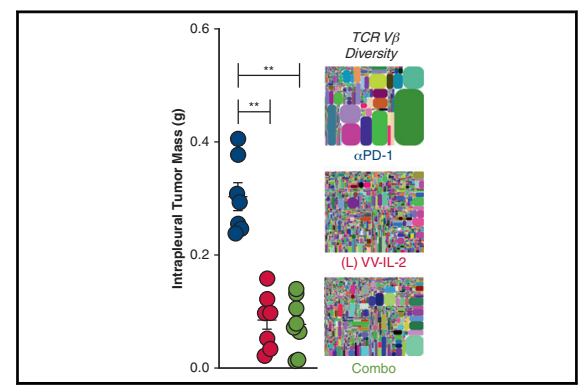

Tumor mass after treatments with associated representative TCR $\mathrm{V} \beta$ diversity tree plot.

\section{CENTRAL MESSAGE}

Intrapleural VV-IL-2 therapy improves local tumor control and $\mathrm{TIL} \alpha \beta$ TCR diversity in a murine model of MPD.

\section{PERSPECTIVE}

There has been limited progress in improving survival for patients with MPE. Immunotherapy is an alternative strategy for patients with metastatic disease in many advanced cancers. Our findings suggest that $\mathrm{V}$ - IL-2 is an effective IL-2-enhanced virotherapy that has the potential to treat patients with refractory MPD.

See Commentaries on pages e329 and e330.

\footnotetext{
From the ${ }^{a}$ Department of Cardiothoracic Surgery, University of Pittsburgh, Pittsburgh, Pa; ${ }^{\mathrm{b}}$ Department of Surgery, University of Pittsburgh, Pittsburgh, Pa; ciRepertoire, Inc, Hudson Alpha Institute for Biotechnology, Huntsville, Ala; ${ }^{\mathrm{d}}$ Department of Immunology, University of Pittsburgh, Pittsburgh, $\mathrm{Pa}$; ${ }^{\mathrm{e}}$ Department of Bioengineering, University of Pittsburgh, Pittsburgh, $\mathrm{Pa}$; ${ }^{\mathrm{f}} \mathrm{Cancer}$ Immunology and Immunotherapy Program, UPMC Hillman Cancer Center, Pittsburgh, Pa; and ${ }^{\mathrm{g}}$ Surgical Services Division, VAPHS, Pittsburgh, Pa.

This project was funded by NCI T32CA113263 to 1 (to C.N.E.); the University of Pittsburgh Department of Cardiothoracic Surgery and Department of Surgery (to R.D., M.T.L.); UPMC Hillman Cancer Center National Cancer Institute Cancer Center Support Grant P30 CA067904; R01CA206012, KC180267, R01 CA236965 to 01A1, R01CA160417 to 07, R01 GM115366 to 05, R01 CA229275 to 01A (to M.T.L.); University of Pittsburgh Dean's Faculty Advancement Award (to R.D.); VA Career Development Award (CX001771-01A2, RD). iRepertoire, Inc (Drs Jian Han and Miranda Byrne-Steele) and the Division of Surgical Oncology (Dr Amer Zuriekat) supported this work. Drs David Bartlett and James Luketich are to be acknowledged for their vision and leadership during
}

the investigation process of this study. All data are available on request through the corresponding author. A public repository of all TCR sequencing data files and associated computational analysis can be found at https://github.com/upmcirep/Ekeke_IL2.

M.T.L. and R.D. contributed equally.

Accepted for the 100th Annual Meeting of The American Association for Thoracic Surgery.

Received for publication May 31, 2020; revisions received Oct 15, 2020; accepted for publication Nov 11, 2020; available ahead of print Dec 13, 2020.

Address for reprints: Rajeev Dhupar, MD, MBA, Department of Cardiothoracic Surgery, 5200 Centre Ave, Suite 715, Pittsburgh, Pa 15232 (E-mail: dhuparr2@upmc edu or Rajeev.dhupar@va.gov).

0022-5223

Published by Elsevier Inc. on behalf of The American Association for Thoracic Surgery. This is an open access article under the CC BY-NC-ND license (http:// creativecommons.org/licenses/by-nc-nd/4.0/).

https://doi.org/10.1016/j.jtcvs.2020.11.160 


$$
\begin{aligned}
& \text { Abbreviations and Acronyms } \\
& \begin{aligned}
\text { D50 } & \text { diversity } 50 \\
\text { IL-2 } & =\text { interleukin } 2 \\
\text { LLC } & =\text { Lewis lung carcinoma } \\
\text { MPD } & =\text { malignant pleural disease } \\
\text { MPE } & =\text { malignant pleural effusion } \\
\text { NSCLC } & =\text { non-small cell lung cancer } \\
\text { OV } & =\text { oncolytic virus } \\
\text { PBS } & =\text { phosphate-buffered saline } \\
\text { PD-1 } & =\text { programmed cell death-1 } \\
\text { TCR } & =\text { T-cell receptor } \\
\text { TIL } & =\text { tumor infiltrating lymphocyte } \\
\text { TME } & =\text { tumor microenvironment } \\
\text { UMI } & =\text { unique molecular identifier } \\
\text { VV } & =\text { vaccinia virus } \\
\text { YFP } & =\text { yellow fluorescent protein }
\end{aligned}
\end{aligned}
$$

anti-programmed cell death-1 reduced tumor burden $(P<.01)$, improved survival $(P<.01)$, and increased intratumoral $\alpha \beta$ T-cell receptor diversity $(P<.05)$ compared with systemic anti-programmed cell death-1 monotherapy.

Conclusions: Intrapleural vaccinia virus-expressing interleukin-2 reduced tumor burden and enhanced survival in a murine malignant pleural disease model. Increased $\mathrm{CD} 8^{+}$tumor-infiltrating lymphocytes and $\alpha \beta$ T-cell receptor diversity are associated with enhanced response. Clinical trials will enable assessment of intrapleural vaccinia virus-expressing interleukin-2 therapy in patients with malignant pleural disease. ( $\mathrm{J}$ Thorac Cardiovasc Surg 2022;163:e313-28)

The incidence of malignant pleural effusion (MPE) is greater than 150,000 cases per year in the United States. A total of $25 \%$ of patients with non-small cell lung cancer (NSCLC) will develop MPE with a median survival of less than 12 months. ${ }^{1-3}$ Despite improvements in systemic and local therapies for patients with early and intermediate stages of NSCLC, there has been limited progress in improving overall survival for those with secondary MPE. ${ }^{1-3}$

Fortunately, immunotherapy provides an alternative strategy for select patients with localized or metastatic disease in many advanced cancers. Oncolytic viruses (OVs) have a demonstrable ability to target and destroy malignant cells without damaging normal tissue and the potential for genetic manipulation to provide immunomodulatory agents within the tumor microenvironment (TME), orchestrating tailored antitumor immunity. ${ }^{4}$ The first Food and Drug Administration-approved OV, Talimogene
Laherparepvec, pioneered the way for clinically effective virotherapy in patients with metastatic melanoma. ${ }^{5,6}$ This genetically modified herpes simplex virus encodes a human granulocyte macrophage colony-stimulating factor gene, promoting immune recruitment and presumed enhanced presentation of tumor antigens subsequent to OV-mediated lysis and resultant antitumor immune response. ${ }^{7}$ Initial phase I and II studies demonstrated both local oncolytic and distant antitumor effects after intratumoral administration. ${ }^{8,9}$ Subsequent trials showed partial $(16 \%)$ and complete responses $(2 \%)$ in patients with advanced melanoma, ${ }^{5}$ leading to its Food and Drug Administration approval.

Metastatic pleural disease has been approached with local administration of recombinant cytokines, including interferon gamma, interferon alpha2b, and interleukin-2 (IL-2), although with minimal long-term clinical impact. ${ }^{4-7}$ IL-2 is a T-cell growth factor that promotes a cellular immune response, enhances cytolytic activity, and drives increases in T-cell number. ${ }^{10}$ Local administration of IL-2 in the pleura is safe and avoids many of the systemic toxic effects. ${ }^{11-14}$ Since 1998, intrapleural IL-2 in combination with cisplatin has been an approved treatment for patients with primary and secondary MPE in China. ${ }^{15}$ Our group recently developed a recombinant vaccinia virus (VV) vector to deliver membrane-bound phosphoinositol glycan-linked IL-2 into the tumor microenvironment. ${ }^{16,17}$ This permits enhanced local delivery of IL-2 with reduced systemic toxicity.

We hypothesized that local treatment of malignant pleural disease (MPD) with a genetically modified OV that expresses membrane-bound IL-2 would result in both an oncolytic and T-cell-mediated antitumor response. In a murine model of metastatic pleural NSCLC, we evaluated the impact of intrapleural VV-IL-2 in reducing tumor burden and prolonging survival. We further assessed its ability to influence the composition and repertoire diversity of $T$ cells infiltrating the tumor with and without immune checkpoint (programmed cell death-1 [PD-1]) inhibition.

\section{MATERIALS AND METHODS Mice}

We used 6- to 8-week-old female C57BL/6 mice purchased from The Jackson Laboratory (Bar Harbor, Me) and housed in the UPMC Hillman Cancer Center Animal Facility. All animal experiments were approved by the University of Pittsburgh Institutional Animal Care and Use Committee. The Lewis lung carcinoma (LLC) cell line expressing red-shifted firefly luciferase (Bioware Brite Cell) was obtained from Perkin Elmer (Waltham, Mass) and cultured in Dubecco's Modified Eagle Medium with $10 \%$ fetal bovine serum, at $37^{\circ} \mathrm{C}$, in a $5 \% \mathrm{CO}_{2}$ incubator.

\section{Oncolytic Virus Preparation}

Oncolytic VVs derived from the Western Reserve strain expressing yellow fluorescent protein (YFP) or membrane-bound IL-2, VV-VV- 

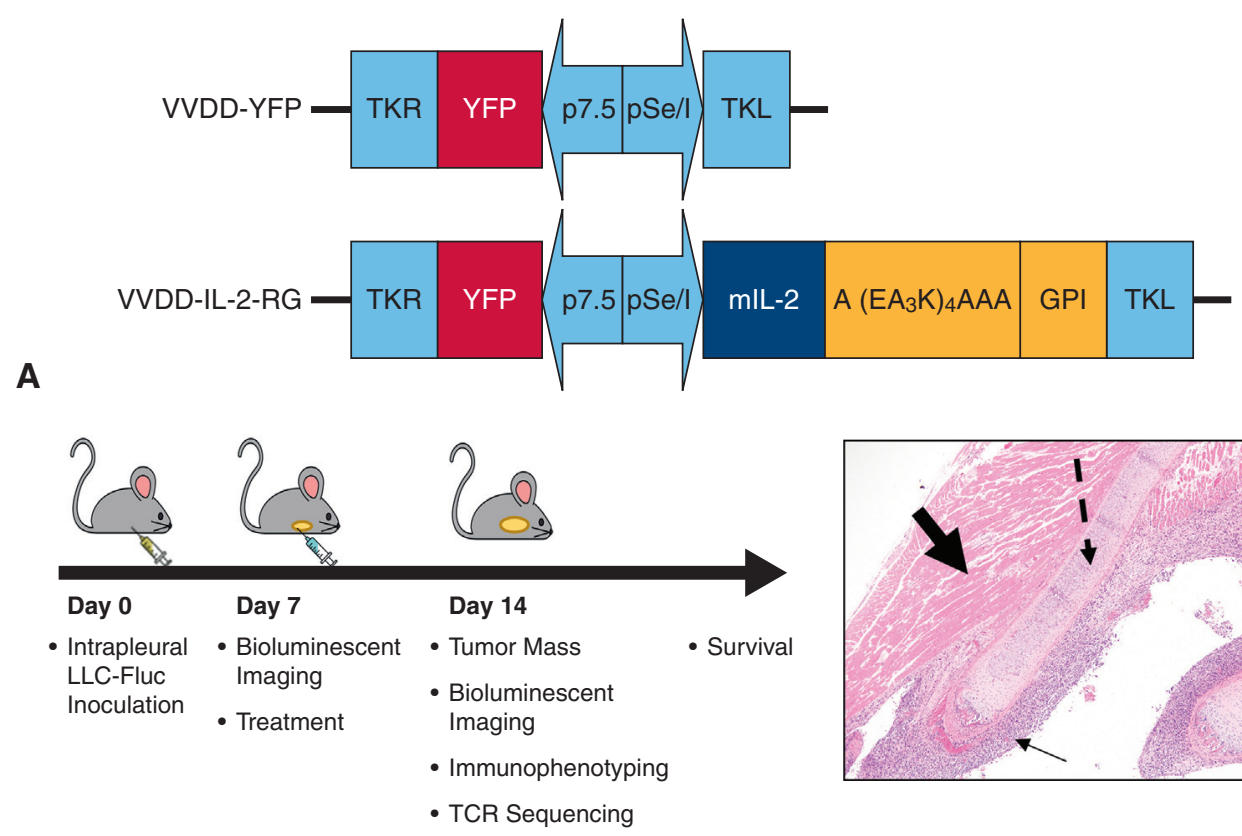

B

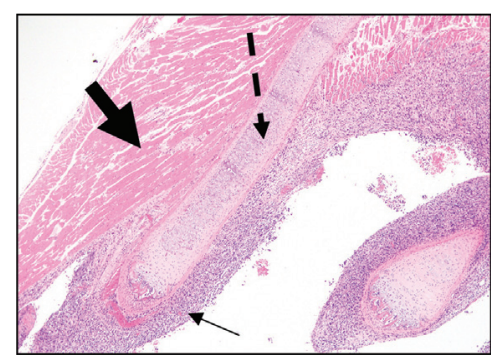

C

FIGURE 1. VV variants and murine model of MPD methodology. A, Doubly deleted VV-YFP expressing membrane bound VV-IL-2 constructs. $\mathrm{B}$, Illustrative display of the timing of experiments to assess day 14 end points and survival after inoculation with tumor and corresponding day 7 treatment. C, Hematoxylin-eosin stain of resected day 7 metastatic pleural disease (solid thin arrow), rib (dashed arrow), and intercostal muscle (bolded arrow) demonstrating successful tumor implantation in the MPD model (10× magnification).

YFP, and VV-IL-2 were used as previously described. ${ }^{16}$ Briefly, plasmid pCMS1-IRES carrying 2 multiple cloning sites separated with an IRES sequence from pLVX-IRES-ZsGreen based on a shuttle plasmid pSEM-1 was constructed. DNA fragments containing the rigid linker fused with a phosphoinositol glycan-linked anchor sequence amplified from human $\mathrm{CD} 16 \mathrm{~b}$ by polymerase chain reaction were inserted into pCMS1-IRES, thus creating plasmid pCMS1-IRESRG. Murine IL-2 cDNA was inserted into pCMS1-IRES-RG to yield pCMS1-IL-2-RG. These shuttle vectors were used for homologous recombination of murine IL-2 variants into the $t k$ gene locus of the vaccinia viral genome. Recombinant viruses were amplified in HEK293 cells as described. ${ }^{16}$

VV expressing reporter gene $(Y F P)$ or IL-2 (Figure 1, $A$ ) viruses were generated. The maximum dose $\left(2 \times 10^{8}\right.$ plaque-forming units $)$ of virus delivering IL-2 without inducing systemic toxicity had been established in extrathoracic murine tumor models. ${ }^{16}$ In vitro replication and cytotoxicity of VV-IL-2 have been demonstrated by our group. ${ }^{16}$

\section{Malignant Pleural Disease Murine Model}

Mice were anesthetized using inhaled isoflurane and oxygen delivery. Intrapleural inoculation with LLC at $5 \times 10^{5}$ cells in $120 \mu \mathrm{L}$ of phosphate-buffered saline (PBS) was delivered percutaneously in the right hemithorax to establish the MPD model. ${ }^{18,19}$ After 1 intraperitoneal dose of D-luciferin $(150 \mu \mathrm{g} / \mathrm{mL})$, tumor burden was monitored by luciferase expression and light emission with a Xenogen IVIS 200 Optical In Vivo Imaging System (Caliper Life Sciences, Hopkinton, Mass). Seven days after tumor inoculation, mice were randomly assigned to various treatment groups: intrapleural PBS control, intrapleural virus (VV-YFP or VV-IL-2), systemic (intraperitoneal) VV-IL-2, or intrapleural viruses in combination with systemic (via peritoneum) anti-PD-1 antibody (clone RMP1-14; Bio X Cell; $200 \mu$ g per injection).
Tumor burden was assessed by bioluminescent imaging as described next. Mice were killed when moribund. Seven days after treatment, bioluminescent imaging was completed and mice were euthanized to harvest spleen tissue and intrapleural tumor nodules (Figure 1, B). Of note, parenteral administration was done via the peritoneal route for all treatments. ${ }^{20}$

\section{Flow Cytometry}

Pleural tumor nodules were harvested into cold PBS and mechanically disaggregated through $70-\mu \mathrm{m}$ filters and suspended in PBS. After centrifugation (Thermo-Scientific [Waltham, Mass]; $4^{\circ} \mathrm{C}, 2100 \mathrm{rpm}$ ), the supernatant was discarded, and residual tumor was resuspended in red blood cell lysis buffer $(1 \times$, BioLegend [San Diego, Calif] $)$; $1.0 \times 10^{6}$ cells per $\mathrm{mL}$ were blocked with $\alpha$-CD16/32 Ab (clone 93; BioLegend: $101319 ; 1: 1000$ ) and stained with antibodies against mouse CD45 (PerCP-Cy5.5; clone 30-F11; BD: 550994;1:200), CD3 (APC-Cy7; clone 145-2C11; BioLegend: 100330; 1:200), CD4 (Alexa700; clone RM4-4; BioLegend: 11,602; 1:200), CD8 (BV785; clone 53-6.7; BioLogend: 1:200), and PD-1 (PE; clone 29F.1A12; BioLegend: 135205; 1:200). Similar procedures were followed to profile circulating lymphocytes in the spleen. Data were collected on a Becton Dickinson (Franklin Lakes, NJ) LSRII Fortessa II (4 and 5 laser) cytometer and analyzed using FlowJo software (v10.6.2). Conventional T-cell and PD-1 gating strategies were completed for all samples and displayed as the percentage positive of all live cells (Figure E1).

\section{Histopathologic Assessment}

Hematoxylin-eosin staining of paraffin-embedded, paraformaldehydefixed samples were performed on harvested pleural tumors in some experiments. 

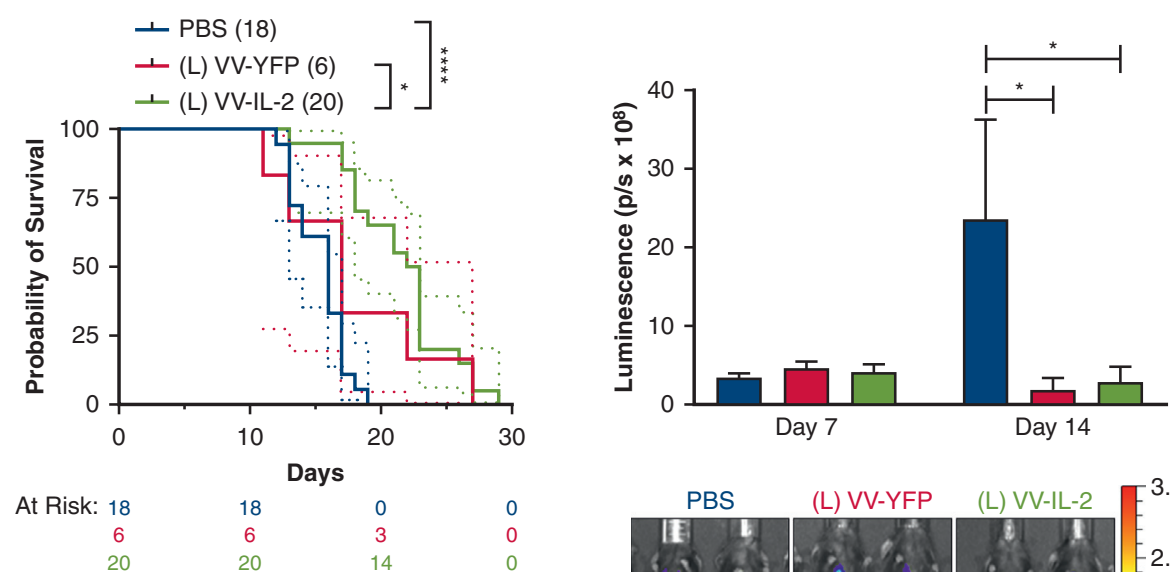

A
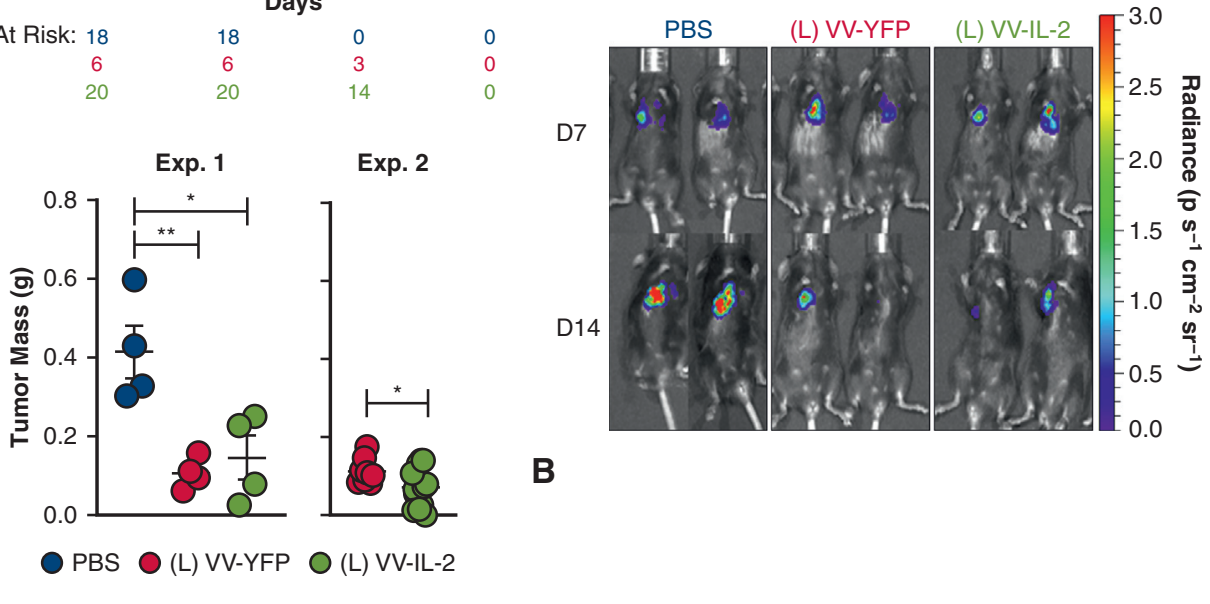

\section{B}

\section{C}
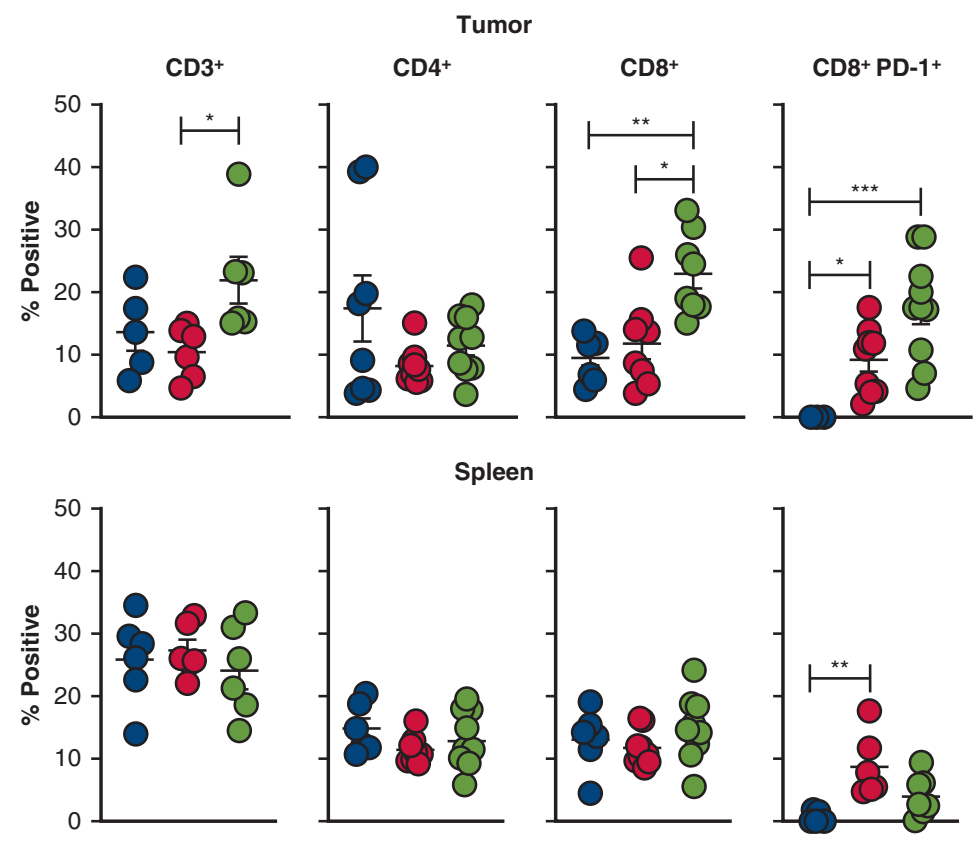

D

PBS O (L) VV-YFP O (L) VV-IL-2

FIGURE 2. IL- 2 VV administration reduces tumor burden and increases PD- $1^{+} \mathrm{CD} 8^{+}$TIL and survival. A, C57BL/6 mice were inoculated with $5 \times 10^{5}$ LLC cells in the intrapleural space and treated 7 days later with PBS $(n=18)$, VV-YFP control $(n=6)$, or VV-IL-2 $(n=20)$ at $2 \times 10^{8}$ plaque-forming units per mouse. Kaplan-Meier survival estimate (with 95\% confidence interval) demonstrate improved survival in the VV-IL-2 group (4 pooled experiments). $\mathrm{B}$, Bioluminescent imaging of MPD mice was completed on days 7 and 14 and cohort mean \pm standard deviation bioluminescence (photons $/ \mathrm{s} \times 10^{8}$ ) are reported (3 separate experiments) with representative mice from each treatment group. C, MPD mice treated with virus showed less tumor burden 7 days 


\section{Amplification, Sequencing, and Bioinformatic Analysis of T-Cell Receptors}

Total RNA was extracted from single cell suspensions of spleen $\left(8.0 \times 10^{6}\right.$ live cells) and tumor (all live cells) using the RNeasy mini kit (Qiagen, Hilden, Germany) according to the manufacturer's protocol. The iR-RepSeq-plus 4-Chain dimer avoidance multiplex polymerase chain reaction amplification sequence (iRepertoire Inc; Huntsville, Ala) was used to generate Next Generation Sequencing libraries covering murine T-cell receptor (TCR)-V $\alpha, \mathrm{V} \beta, \mathrm{V} \gamma$, and $\mathrm{V} \delta$, chains. A total of $1000 \mathrm{ng}$ of extracted RNA was amplified in a single assay incorporating unique molecular identifiers (UMIs) during the reverse transcription step by the Biomek-i5 workstation (Beckman Coulter, Brea, Calif) as described previously. $^{21-23}$ Amplified libraries were multiplexed and pooled for sequencing on the Illumina NextSeq V2.5 platform with a 300-cycle kit. Each sample was allotted 4 million total sequencing reads. Raw data were demultiplexed, and UMI-guided assembly was performed using migec v1.2.9, and the resulting consensus fastqs were aligned and assembled into clonotypes using mixcr v3.0.14. ${ }^{24-26}$ The output T-cell receptor sequence covers FR2 to FR4, as well as the beginning of the constant region.

Raw data were analyzed using the previously described iRmap program (iRepertoire). ${ }^{21,22}$ Total reads were normalized to generated UMIs and unique CDR3s, shared spleen and tumor CDR3s, the diversity 50 (D50) or percent of unique CDR3s that account for $50 \%$ of the "head" TCR repertoire, ${ }^{23}$ clonality (1-Pielou's Index), ${ }^{27}$ and Alpha Index (the percentage of reads that the single largest clone occupies within the "head" of the entire TCR repertoire, where the "head" is defined as number of reads of clones equal to or greater than the mean expression of the total dataset) were compared across the 4 TCR chains between treatment groups.

\section{Statistical Analysis}

Results are reported from at least 2 independent experiments performed with at least triplicate samples. Statistical analysis was performed using Student 2-tailed $t$ test for comparisons of 2 groups or Kruskal-Wallis 1-way analysis of variance for multiple groups (GraphPad Prism 8; San Diego, Calif). Survival analyses were conducted from the date of tumor inoculation using the Kaplan-Meier method.

\section{RESULTS}

\section{Intrapleural Vaccinia Virus Interleukin-2 Reduces Tumor Burden and Improves Survival in Malignant Pleural Disease Mice}

To evaluate the efficacy of oncolytic virotherapy, mice were administered LLC cells in the pleural cavity resulting in MPD 7 days after inoculation as indicated by histopathology (Figure 1,C). We first determined whether local intrapleural administration of VV-IL-2 could induce a superior therapeutic response compared with PBS or the vaccinia viral control, VV-YFP. At 7 days postinoculation, mice received a single administration of intrapleural PBS, VV-YFP, or VV-IL-2. There were no signs of distant metastasis on gross autopsy after tumor inoculation or treatment administration. Median overall survival was improved in the MPD mice treated with VV-IL-2 (23 days) when compared with PBS (16 days, $P<.001)$ or VV-YFP (17 days) $(P<.05$; Figure $2, A)$. The day 14 tumor bioluminescence was lower in the VV-IL-2 group compared with PBS $(P<.05)$, but not different from the VV-YFP group (Figure 2, $B$ ). However, reduction in tumor volume was significantly enhanced in mice treated with VV-IL-2 when compared with the VV-YFP $(P<.05$; Figure $2, C$ ). Inclusion of VV-YFP in this study enabled comparison of the IL-2-mediated treatment effect compared with no treatment (PBS) or OV (VV-YFP) alone.

\section{Intrapleural Vaccinia Virus Interleukin-2 Increases CD8 $^{+}$T-Cell Tumor Infiltration}

We hypothesized that the antitumor efficacy after intrapleural VV-IL-2 resulted from an IL-2-mediated increase in tumor infiltrating lymphocytes (TILs). Thus, we analyzed TIL populations after treatment by flow cytometry. Despite no absolute difference in $\mathrm{CD}^{+} \mathrm{TIL}$ ( $\%$ of total live cells) when comparing VV-YFP and PBS controls, administration of VV-IL-2 resulted in an increased proportion of total $\mathrm{CD}^{+}(P<.05)$ and $\mathrm{CD}^{+} \mathrm{T}$ cells $(P<.01)$, with no significant difference in $\mathrm{CD} 4^{+}$TIL in MPD tumors (Figure 2,D). No significant changes in the relative abundance of $\mathrm{CD}^{+}, \mathrm{CD}^{+}$, or $\mathrm{CD}^{+} \mathrm{T}$ cells were found in the spleen with VV-YFP treatment (Figure 2, D). Collectively, our results indicate that intrapleural VV-IL-2 results in increased TIL and particularly $\mathrm{CD}^{+}$TIL with associated reduced tumor burden when compared with the VV-YFP and PBS controls.

\section{Intrapleural Vaccinia Virus Interleukin-2 Decreased Tumor Burden and Improved Survival in Malignant Pleural Disease Mice Compared With Systemic Vaccinia Virus Interleukin-2}

Having established the relative efficacy of VV-IL-2 in our MPD model, we compared the antitumor efficacy of systemic versus intrapleural VV-IL-2 in MPD mice. Median survival was improved after intrapleural versus systemic VV-IL-2 (23 vs 18 days; $P<.05$ ) (Figure 3, $A$ ), and although there was no difference in day 14 tumor bioluminescence (Figure $3, B$ ), tumor burden was decreased in the intrapleural group $(P<.001$; Figure 3, $C)$.

Intrapleural and systemic VV-IL-2 resulted in increased $\mathrm{CD}^{+}$TIL $(P<.05)$, whereas only intrapleural VV-IL-2 increased $\mathrm{CD}^{+}(P<.01)$ and $\mathrm{CD}^{+}$TIL $(P<.05)$ compared with intrapleural VV-YFP control (Figure 3,

\footnotetext{
after virus treatment ( 2 separate experiments). D, MPD mice were killed 7 days after treatment and tumor and spleen sample were analyzed by flow cytometry. Flow cytometry analysis $\mathrm{CD}^{+}, \mathrm{CD} 4^{+}, \mathrm{CD}^{+}$, and $\mathrm{CD} 8^{+} \mathrm{PD}-1^{+}$expression (percent of all live cells) of immune cells demonstrated an overall increase in $\mathrm{CD}^{+}$tumor infiltration and specifically $\mathrm{CD} 8^{+}$(but not $\mathrm{CD} 4^{+}$) and $\mathrm{CD} 8^{+} \mathrm{PD}-1^{+} \mathrm{T}$ cell with VV-IL-2 treatment $(3$ separate experiments). The same immune populations were not altered in the spleen, except for increased $\mathrm{CD} 8^{+} \mathrm{PD}-1^{+}$cells with VV-YFP treatment compared with PBS. $P$ values are reported $(* P<.05, * * P<.01, * * * P<.001)$.
} 

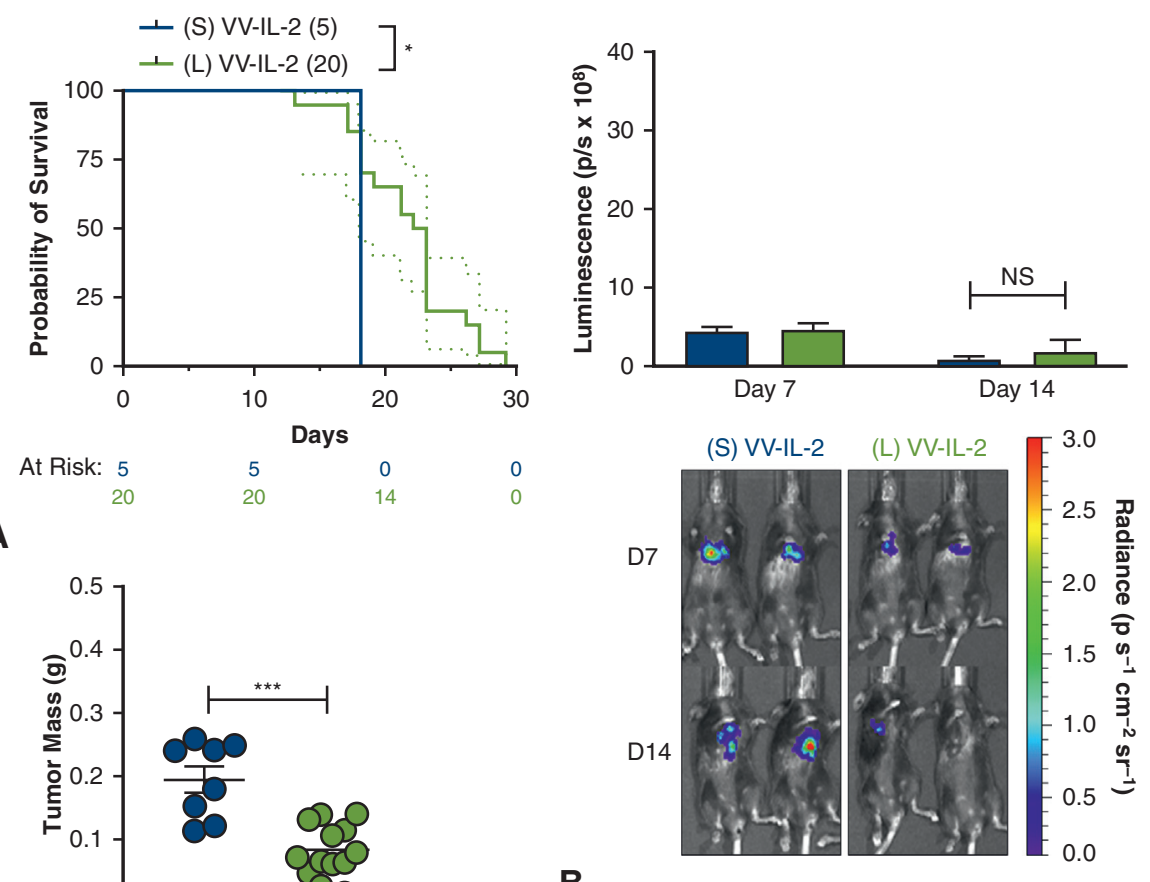

A

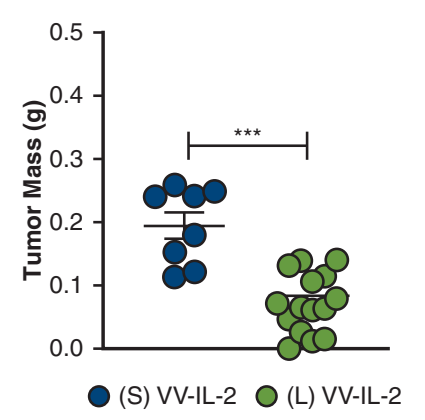

C
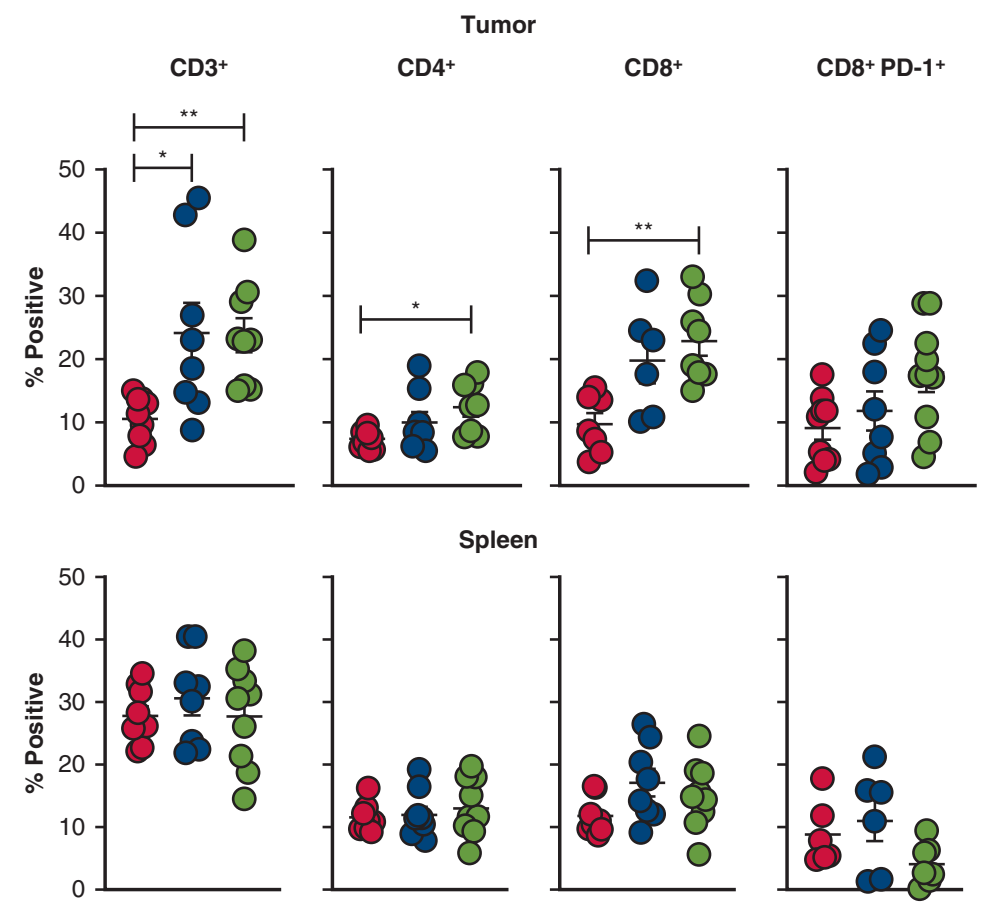

D

(L) VV-YFP

(S) VV-IL-2

(L) VV-IL-2

FIGURE 3. Intrapleural IL-2 expressing VV demonstrates superior antitumor efficacy compared with systemic (intraperitoneal) administration. A, Kaplan-Meier survival estimate (with 95\% confidence interval) for MPD mice treated with systemic VV-IL-2 (n = 5) or intrapleural VV-IL-2 $(\mathrm{n}=20)$ at $2 \times 10^{8}$ pfu per mouse 7 days post-tumor inoculation (2 pooled experiments) demonstrates survival benefit with intrapleural VV-IL-2 treatment. $\mathrm{B}$, There was no difference in tumor bioluminescence (photons $/ \mathrm{s} \times 10^{8}$ ) between systemic and local VV-IL-2 in bioluminescence ( 3 separate experiments). $\mathrm{C}$, Intrapleural VV-IL-2 resulted in less tumor burden ( 2 pooled experiments). D, Flow cytometry analysis of CD $3^{+}, \mathrm{CD} 4^{+} \mathrm{CD} 8^{+}$, and CD8 ${ }^{+} \mathrm{PD}-1^{+}$(percent of all live cells) immune populations showed elevated intratumoral $\mathrm{CD} 3^{+}$both systemic and local VV-IL-2, but only increased $\mathrm{CD} 4^{+}$and $\mathrm{CD} 8^{+}$infiltrate after intrapleural VV-IL-2 versus VV-YFP control ( 3 separate experiments). The same immune populations were not altered in the spleen. $P$ values are reported $(* P<.05, * * P<.01, * * * P<.001)$. 

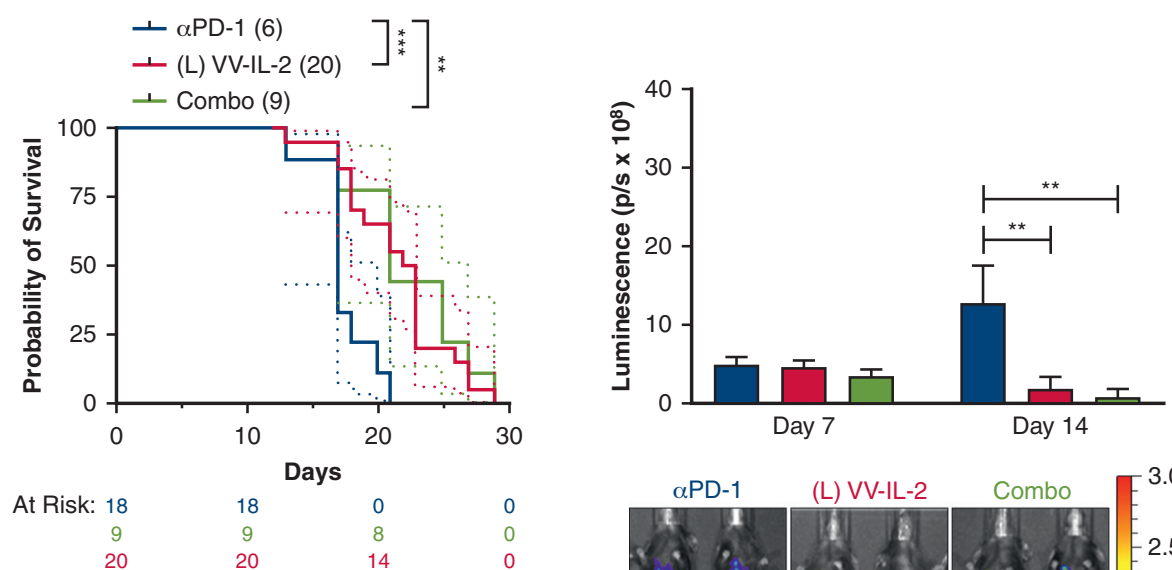

A
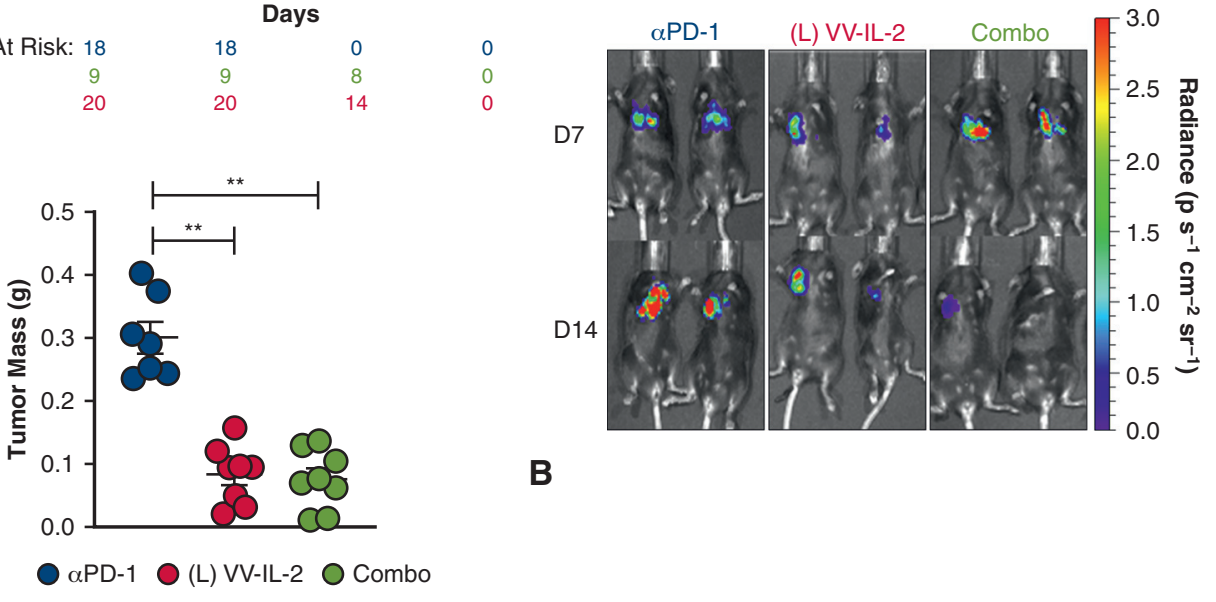

B

C
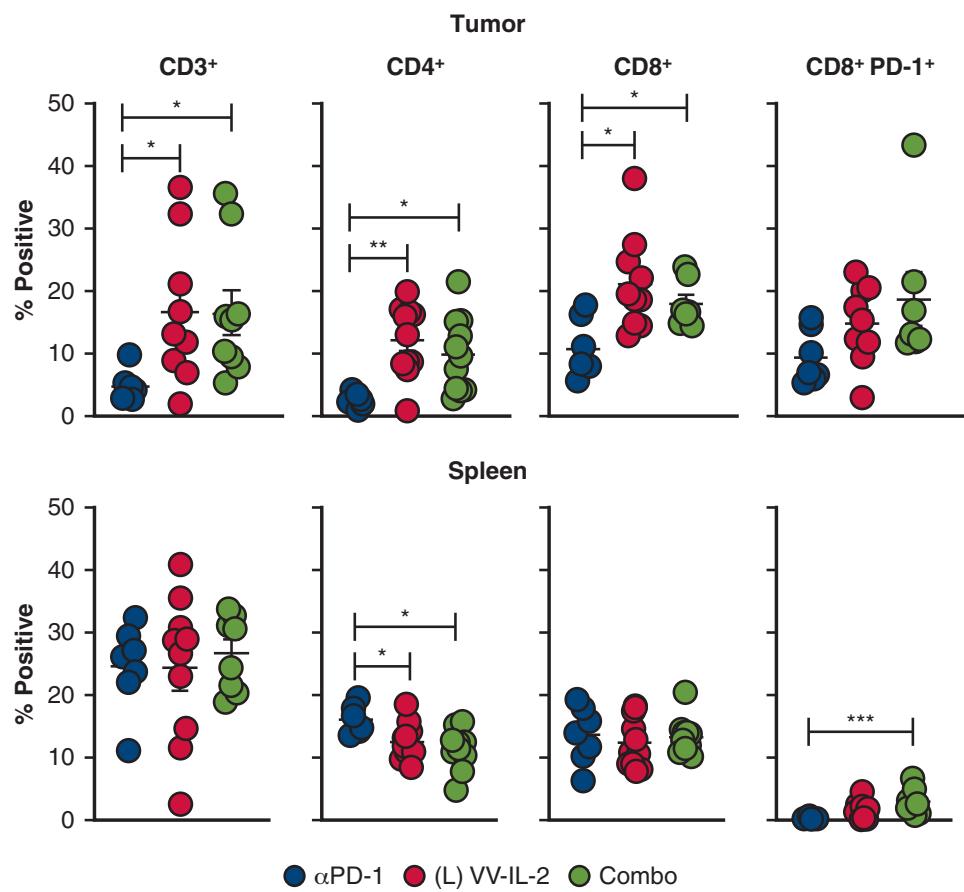

D

FIGURE 4. PD-1 antibody therapy in combination with intrapleural VV-IL-2 provides comparable efficacy and TIL infiltration. A, MPD mice were treated with systemic anti-PD-1 $(n=9)$, intrapleural VV-IL-2 $(n=20)$, or combination therapy ( $n=9)$; (2 pooled experiments). Kaplan-Meier survival estimate (with $95 \%$ confidence interval) demonstrate that combination therapy or VV-IL-2 alone improved survival compared with anti-PD-1 alone. B, Bioluminescent imaging at days 7 and 14 showed evidence of tumor regression at day 14 in the combination and VV-IL-2 cohort compared with anti-PD-1 alone. C, Combination therapy or VV-IL2 alone decreased tumor mass compared with anti-PD-1 only treatment. D, Flow cytometry analysis of the immune infiltrates of the tumor for $\mathrm{CD}^{+}, \mathrm{CD}^{+}, \mathrm{CD}^{+}$, and $\mathrm{CD} 8^{+} \mathrm{PD}-1^{+}$expression (percent of all live cells) demonstrate no difference between combination therapy versus VV-IL-2 alone. However, enhanced adaptive immunity through increased $\mathrm{CD}_{3}^{+}, \mathrm{CD}^{+}$, and $\mathrm{CD}^{+}$immune cell infiltration was evident after local VV-IL-2 or combination treatment (compared with systemic anti-PD-1 only). Splenocytes demonstrated decreased CD $4^{+}$and elevated CD ${ }^{+}$PD- 1 expressing T cells after combination therapy compared with systemic anti-PD-1 alone. $P$ values are reported $(* P<.05, * * P<.01, * * * P<.001)$. 

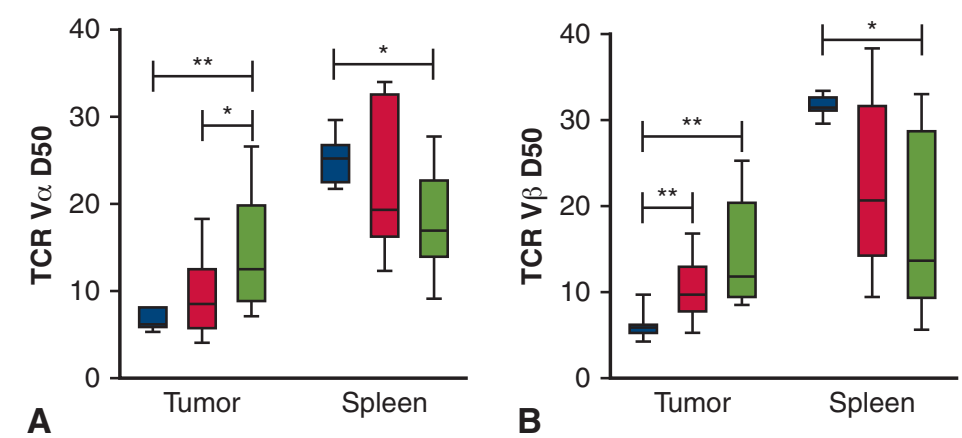

$\square$ QPD-1 $\square(\mathrm{L}) \mathrm{VV}-\mathrm{IL}-2 \quad \square$ Combo

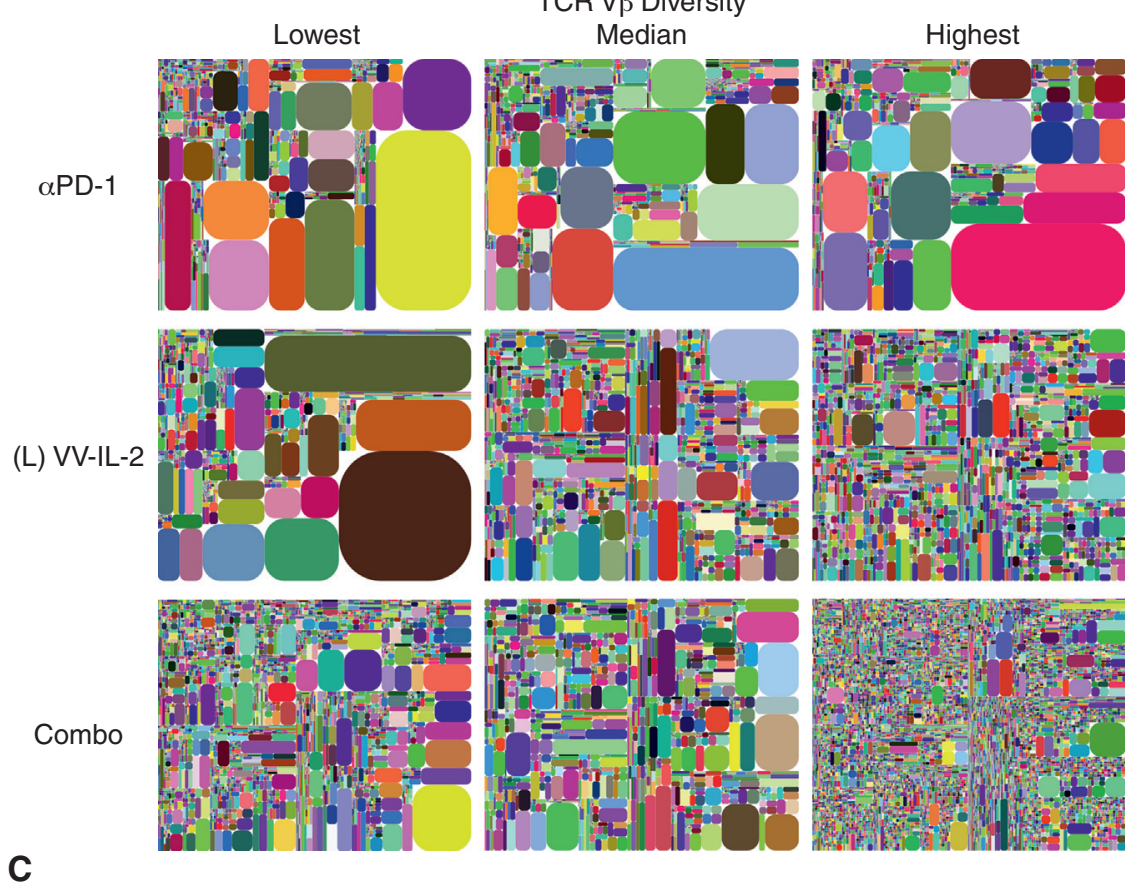

FIGURE 5. Combination VV-IL-2 and anti-PD-1 Ab therapy increases intratumoral $\alpha \beta$ TCR diversity. Unbiased pan-TCR dimer avoidance multiplex polymerase chain reaction and next-generation sequencing were completed on RNA extracted from all live TIL and $8 \times 10^{6}$ live spleen cells. $\mathrm{A}, \mathrm{V} \alpha \mathrm{D} 50$ and (B) V $\beta$ D50 were assessed in tumor and spleen across systemic anti-PD-1 alone $(\mathrm{n}=7)$, intrapleural VV-IL-2 alone ( $\mathrm{n}=9)$, and combination anti-PD-1 and VV-IL-2 $(n=8)$. Although VV-IL-2 treatment increased TIL TCR V $\beta$ D50, combination treatment increased TIL TCR V $\alpha$ and V $\beta$ D50 compared with anti-PD-1 treatment. $\mathrm{C}, \mathrm{V} \beta$ Intratumoral repertoire diversity is illustrated in tree maps where each rounded rectangle represents a unique CDR3, with the size of the rectangle corresponding to the relative frequency of the CDR3 clones across the entire distribution. Representative tree maps shown for anti-PD-1, VV-IL-2, and combination treatment, with samples with minimum, median, and maximum diversity from left to right. $P$ values are reported $(* P<.05, * * P<.01)$.

$D$ ). No differences in lymphocyte counts were observed in the spleen after systemic or intrapleural treatment (Figure 3,D).

Combination Intrapleural Vaccinia Virus

Interleukin-2 and Systemic Anti-Programmed Cell Death-1 Antibody Results in Decreased Tumor Burden With Increased Immune Infiltration

Combination therapies (eg, checkpoint inhibitors and OVs) have promise in promoting an enhanced adaptive immune response. ${ }^{28,29}$ Given the increase in PD-1 expressing $\mathrm{CD}^{+} \mathrm{T}$ cells after intrapleural VV-YFP $(P<.05)$ or VV-IL-2 $(P<.001$, Figure $2, D)$, we hypothesized that systemic blockade of PD-1 signaling on $\mathrm{CD}^{+} \mathrm{T}$ cells would inhibit local immunosuppression in the TME and promote a synergistic antitumor effect after intrapleural VV-IL-2 in MPD mice.

Combination therapy resulted in improved survival compared with systemic anti-PD-1 antibody alone (21 vs 16 days; $P<.01$ ), but no difference when compared with 

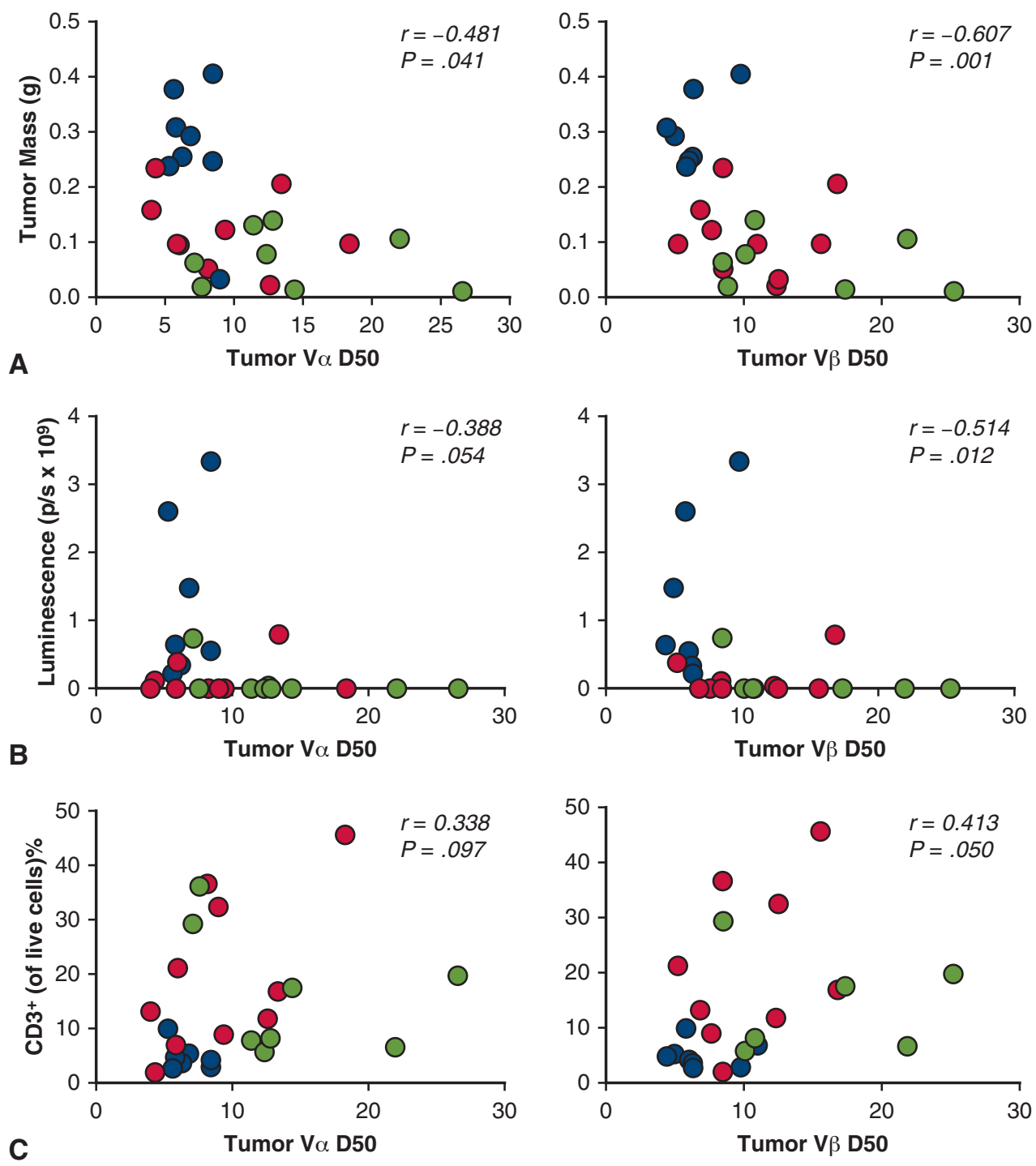

$\alpha P D-1 \bigcirc(L) V V-I L-2 \bigcirc$ Combo

FIGURE 6. Intratumoral $\alpha \beta$ TCR diversity correlates with tumor burden and T-cell infiltrate. To better understand the relationship of intratumoral TCR diversity and murine tumor response, tumor mass (A), day 14 bioluminescence (B), and intratumoral CD $3^{+} \mathrm{T}$ cells (C) were correlated with both TIL V $\alpha$ and $\mathrm{V} \beta$ D50. Spearman correlation coefficient and $P$ values are reported suggesting a negative correlation between TCR V $\alpha \beta$ D50 and tumor burden (tumor mass and bioluminescence) and a positive correlation between TCR V $\alpha \beta$ D50 and TIL CD $3^{+}$counts.

VV-IL-2 alone (Figure 4, A). Reduction in tumor bioluminescence was observed on day 14 after combination therapy administration compared with systemic PD-1 blockade (Figure 4, B). Tumor mass was similar between combination therapy and intrapleural VV-IL-2, with both resulting in reduced tumor burden compared with systemic anti-PD-1 alone $(P<.01$, Figure $4, C)$. There were a higher number of $\mathrm{CD}^{+}, \mathrm{CD}^{+}$, and $\mathrm{CD}^{+}$TIL $(P<.05)$ but no difference in $\mathrm{PD}-1$ expressing $\mathrm{CD}^{+} \mathrm{T}$ cells after combination therapy or intrapleural VV-IL-2 when compared with systemic anti-PD-1 alone (Figure 4, D). Additionally, the combination or intrapleural VV-IL-2 alone groups had a reduction in splenic $\mathrm{CD}^{+} \mathrm{T}$ cells compared with systemic anti-PD-1 $(P<.05$; Figure 4, D).

Combination Intrapleural Vaccinia Virus

Interleukin-2 and Systemic Anti-Programmed Cell

Death-1 Antibody Increase Intratumoral $\alpha \beta$ T-Cell

Receptor Diversity

To further classify the effect of combination intrapleural VV-IL-2 and systemic anti-PD-1 antibody on the infiltrating and systemic immune composition, we completed unbiased single reaction pan-TCR amplification 

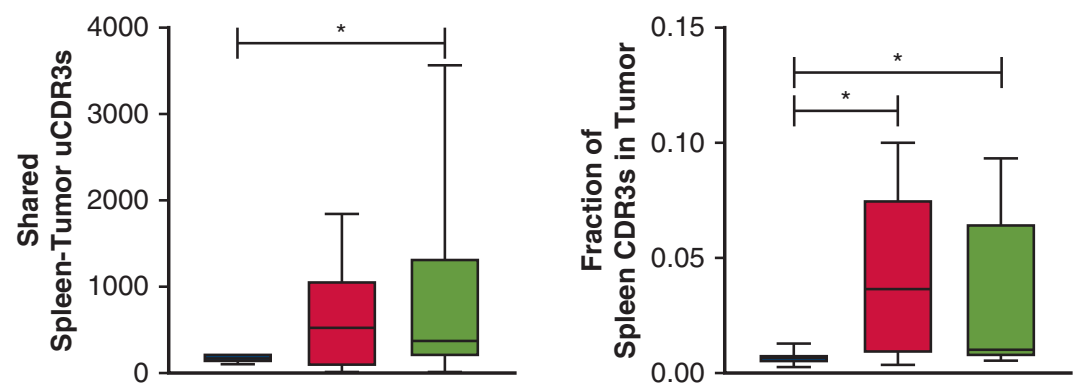

A

\section{B}

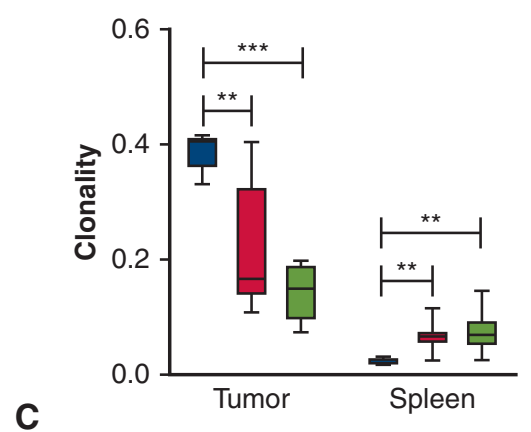

D

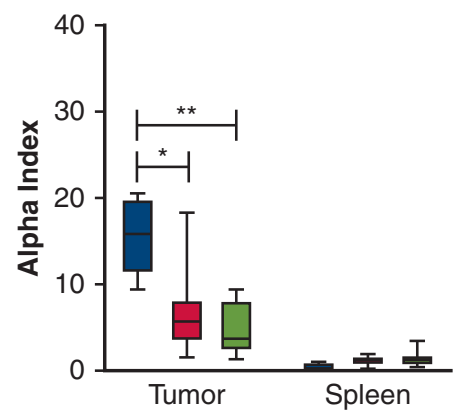

$\alpha \mathrm{PD}-1$

(L) VV-IL-2 $\square$ Combo

FIGURE 7. Altered spleen-tumor TCR V $\beta$ sharing and clonality with intrapleural VV-IL-2 therapy To identify changes in the splenic and tumor CDR3 migration and expansion, (A) the absolute number of shared TCR V $\beta$ unique CDR3s between tumor and spleen was compared across systemic anti-PD-1 alone $(\mathrm{n}=7)$, intrapleural VV-IL-2 alone $(\mathrm{n}=9)$, and combination anti-PD-1 and VV-IL-2 $(\mathrm{n}=8)$ treatment in the MPD mouse model. Compared with mice treated with anti-PD-1, combination therapy increased the number of shared TCR V $\beta$ unique CDR3s. B, The fraction of spleen TCR V $\beta$ CDR3s found in TIL TCRs was increased with VV-IL-2 treatment compared with anti-PD-1 therapy. C, TCR V $\beta$ clonality and the (D) alpha index, measures of highly clonal populations, were compared between spleen and tumor across treatments. Anti-PD-1 treated TILs exhibited the highest clonality with VV-IL-2 and combination therapy increasing spleen-specific clonality. $P$ values are reported $(* P<.05, * * P<.01, * * * P<.001)$.

and next-generation sequencing to assess TCR diversity as previously described. ${ }^{21,22}$ Each sample was allotted approximately 4 million total sequencing reads. As expected, the mRNA expression of unique CDR3s was considerably elevated in the spleen when compared with tumor, irrespective of treatment (Figure E2, $A-D$ ). ${ }^{30,31} \alpha \beta$ $\mathrm{TCR}^{+}$cells expressing the $\mathrm{V} \alpha$ and $\mathrm{V} \beta$ transcripts comprised the majority of the tumor infiltrating and systemic $\mathrm{T}$ lymphocytes, with a paucity of $\mathrm{V} \gamma$ or $\mathrm{V} \delta$ expressing cells (Figure E2, $A-D$ ). Given the long tail distribution of the T-cell repertoires, we calculated the D50, or percent of unique CDR3s that account for $50 \%$ of the head of the distribution (mean expression or higher), as a measure of TCR diversity. ${ }^{23}$ Combination therapy, but not intrapleural VV-IL-2 alone, increased intratumoral $\mathrm{V} \alpha$ D50 compared with systemic anti-PD-1 monotherapy $(P<.01)$ and intrapleural VV-IL-2 alone $(P<.05$, Figure $5, A)$. Both VV-IL-2 and combination therapy also proportionally increased intratumoral V $\beta$ D50 compared with anti-PD-1 monotherapy $(P<.05$, Figure $5, B$ and $C)$. Similar results were observed when comparing the Shannon diversity index, which encompasses the entire
TCR distribution $(P<.05$, Figure E3), as previously profiled in murine repertoire studies. ${ }^{30,31}$

The intratumoral $\mathrm{V} \beta$ D50 displayed a negative correlation with resected tumor mass $(\mathrm{r}=-0.607$, $P=.001$, Figure $6, A)$ and tumor bioluminescence $(\mathrm{r}=-0.514, P=.012$, Figure $6, B)$, and a positive correlation with infiltrating $\mathrm{CD}^{+} \mathrm{T}$ cells $(\mathrm{r}=0.413$, $P=.050$, Figure $6, C$ ). Similar correlations were observed for intratumoral $\mathrm{V} \alpha$ D50 (Figure 6, $A-C$ ).

\section{Altered Spleen-Tumor T-Cell Receptor V $\beta$ Sharing and Clonality With Intrapleural Vaccinia Virus Interleukin-2 Therapy}

Given the high tumor mutational burden in patients with NSCLC and the critical importance of clonal expansion of neoantigen reactive TIL in patients with durable complete responses to immunotherapy, we sought to further characterize the T-cell repertoire clonality after $\mathrm{OV}$ therapy. ${ }^{27,32}$ Both $\mathrm{VV}$ treatments demonstrated reduced systemic (splenic) $\mathrm{V} \alpha$ and $\mathrm{V} \beta$ D50 compared to anti-PD1 monotherapy $(P<.05$, Figure $5, A$ and $B)$. Combination therapy increased the absolute number of shared unique 


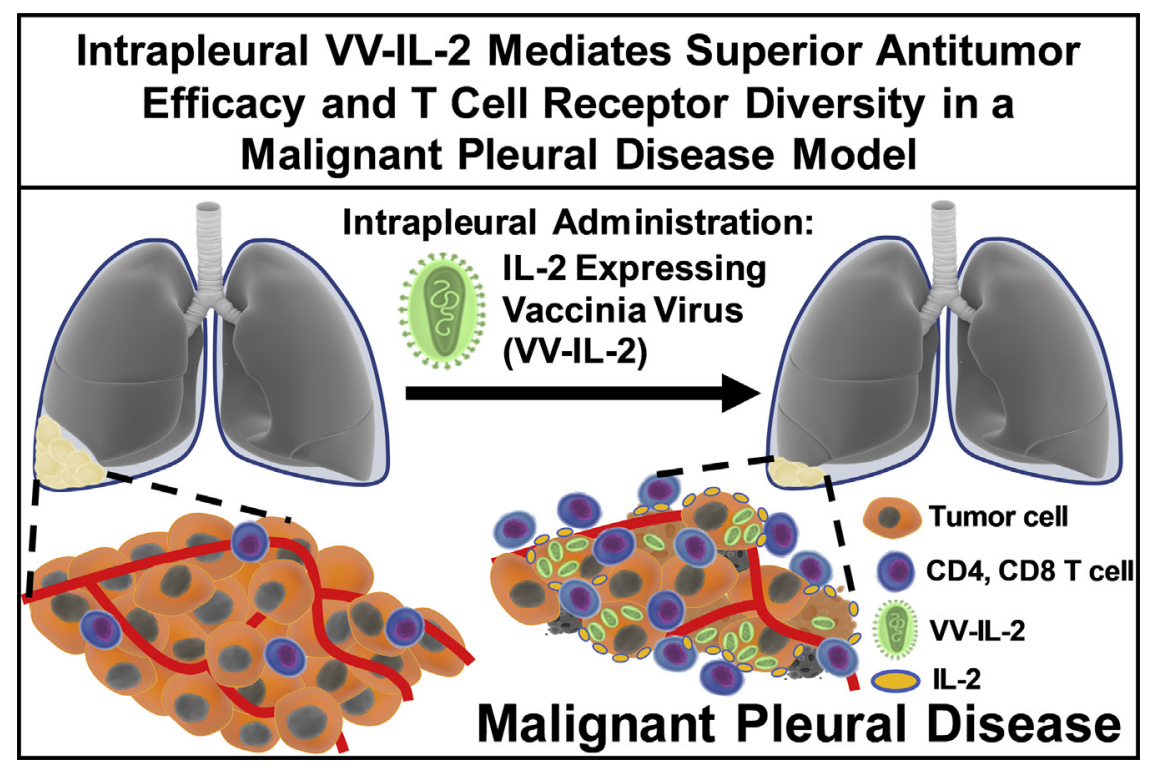

FIGURE 8. Intrapleural IL-2 expressing oncolytic virotherapy mediates superior antitumor efficacy and enhances T-cell receptor diversity in an MPD model. Local administration of an IL-2 expressing VV reduces tumor burden, which is associated with increased CD4 $4^{+}$and $\mathrm{CD} 8^{+} \mathrm{T}-\mathrm{cell}$ infiltrate and $\alpha \beta$ T-cell receptor diversity in an MPD model.

CDR3s between the spleen and tumor of an individual mouse compared with anti-PD-1 therapy $(P<.05$, Figure 7, A). VV-IL-2 and combination and treatment increased the proportion of circulating splenic CDR3s found within TIL compared with that of anti-PD-1 therapy $(P<.05$, Figure $7, B)$. TCR clonality was significantly higher among TIL populations with anti-PD-1 treatment $(P<.01$, Figure 7, $C)$, whereas the splenic repertoire was more clonal in mice receiving VV-IL-2 or combination therapy $(P<.05$, Figure $7, C)$. This finding, along with assessment of the Alpha Index, or percentage of CDR3s occupied by the single largest clone within the "head" distribution of the repertoire, which was decreased among TILs with both VV treatments compared with anti-PD-1 $(P<.05$, Figure $7, D)$, supported our previous finding that VV-IL-2 treatment elicits enhanced diversity of $\mathrm{T}$ cells within the tumor.

\section{DISCUSSION}

MPD is a terminal event for many patients with cancer. The mainstay of treatment includes systemic cytotoxic, molecularly targeted, or immune therapies with palliative drainage. Our study evaluated the antitumor efficacy and resulting TIL immunophenotype in an experimental murine model of MPD using intrapleural and systemic delivery of oncolytic VV-IL-2, systemic anti-PD-1 antibody, and combination therapy. The key findings were (1) intrapleural VV-IL-2 reduces tumor burden, prolongs survival, and promotes $\mathrm{CD}^{+}$T-cell tumor infiltration; (2) intrapleural VV-IL-2 was superior to systemic delivery; and (3) the addition of systemic anti-PD-1 antibody did not improve tumor efficacy, but resulted in increased intratumoral TCR diversity and expansion of splenic clones (Figure 8).

Over time, localized therapy in MPD has not garnered enthusiasm because of the generally short survival of patients and limited efficacy. In China, intrapleural IL-2 with cisplatin has been effective in improving survival for patients with MPE from NSCLC; however, the benefits are modest, and it has not become a widely adopted strategy outside of China. ${ }^{15}$ Intrapleural VV-IL-2 therapy, with direct antitumor effects and promoting increased $\mathrm{CD}^{+}$T-cell infiltration, renews interest in the potential benefits of such localized therapies. Several preclinical and clinical studies evaluating the efficacy of the OVs in MPD highlight the translational relevance of this approach in patients with solid tumors. Therapeutic efficacy of a measles virus was demonstrated in a breast cancer MPE murine model. Intravenously and intrapleurally administered virus resulted in high viral replication and syncytia formation in the pleural tumor deposits and improved median survival by approximately $80 \%$ compared with the PBS control mice. ${ }^{33}$ A phase I study of intrapleural administration of the VV GL-ONC1 in patients with MPEs from malignant pleural mesothelioma $(\mathrm{n}=11)$, NSCLC $(\mathrm{n}=1)$, or breast cancer $(\mathrm{n}=1)$ suggested a tolerable safety profile with positive infection identified in 6 of 8 evaluated patients. ${ }^{34}$ Although treated patients with NSCLC or breast cancer progressed quickly, GL-ONC1 was best suited for patients with MPM whose disease is limited to the pleural space as 5 of 9 patients with MPM had time to progression 9 months or more. The safety profile of intrapleural administration of the 
granulocyte macrophage colony-stimulating factor expressing Talimogene Laherparepvec $\mathrm{OV}$ is being evaluated in conjunction with systemic anti-PD-1 inhibition in patients with MPE secondary to NSCLC (NCT03597009). IL-2-mediated activation and expansion of $\mathrm{T}$ cells to elicit a tumor specific response using our $\mathrm{OV}$ holds promise for use in MPEs that result from a variety of cancer types.

Checkpoint inhibitors (specifically anti-PD-1 antibodies) are a frequently used systemic treatment in patients with advanced NSCLC. Our finding that $\mathrm{CD} 8^{+} \mathrm{TIL}$ in our MPD murine model had higher expression of PD-1 after treatment with VV-IL-2 prompted us to test a combination of systemic anti-PD-1 antibody with localized OV. Although we did not identify measurable differences in tumor burden and survival, the increase in TIL TCR diversity and clonal expansion in the spleen are novel findings. The advent of dimer avoidance multiplex polymerase chain reaction and next-generation sequencing technologies has enabled more comprehensive analysis of the immune repertoire in relation to cancer development and treatment. ${ }^{23,35}$ Response and overall survival after immune checkpoint blockade in patients with metastatic NSCLC correlates with pretreatment systemic $\mathrm{CD} 8^{+} \mathrm{PD}^{-} 1^{+} \mathrm{V} \beta$ diversity ${ }^{36}$ and higher TCR productive frequencies. ${ }^{37} \mathrm{~A}$ recent report has suggested that in patients with early-stage NSCLC demonstrating significant TCR homology between TIL and T cells in healthy adjacent lung exhibit worse survival, presumably due to a less specific antitumor immune response. ${ }^{27}$ Our finding that MPD mice treated with combination systemic checkpoint and intrapleural OV had increased TIL TCR diversity and reduction in the Alpha Index suggests that this combination may enhance the breadth of the tumor-specific immune response. The enhanced clonality with PD-1 antibody therapy suggests a possible liability of this approach, particularly when used alone and without chemotherapy ${ }^{38}$ or antibodies to CTLA $4,{ }^{39}$ which have demonstrable greater efficacy in patients.

Evaluation of multiple immunotherapies (anti-PD-1, anti-CTLA-4, anti-4-1BB, anti-CD-4) in a B16 melanoma model enhanced intratumoral $\mathrm{V} \beta$ diversity in all treated animals. ${ }^{30}$ In the current study, the increased intratumoral $\mathrm{V} \alpha$ and $\mathrm{V} \beta$ diversity was also found with VV-IL-2 ( $\mathrm{V} \alpha$ only) administration alone and in combination with anti-PD-1. Irrespective of treatment, $\alpha \beta$ TCR diversity also correlated with decreased tumor burden and increased $\mathrm{CD}^{+}{ }^{+}$immune infiltrate, indicating the critical role of generating a diverse immune repertoire to control tumor growth. Evidence of clonal expansion of tumor reactive TCRs after administration of IL-2 expressing VV was also observed with a constant overall number of unique CDR3s in spleen and tumor and increased splenic clonality. However, tumor specific clonal expansion may have been limited by the immunosuppressive TME and limited time course afforded by the used model remains to be investigated. The contribution of IL-2 versus VV-mediated enhancement of intratumoral $\alpha \beta$ TCR diversity is currently under investigation. The improved antitumor efficacy of intrapleural versus systemic VV-IL-2 underscores the improved oncolytic effect of local administration. Combination systemic and local OV strategies may enhance antitumor effects by facilitating recognition and eradication of distant metastases via systemic administration, in conjunction with more focused local treatment. Local and systemic VV (VV.mIFN $\beta$ and VV.Luc) have been tested in subcutaneous murine models of NSCLC with a $40 \%$ reduction in tumor burden. ${ }^{40}$ Additional studies with VV-IL-2 are planned to evaluate antitumor efficacy alone and in combination with adoptive cellular therapy. By increasing infiltration of $\mathrm{CD}^{+} \mathrm{T}$ cells and enriching TIL repertoire diversity, our study serves as the basis for using oncolytic virotherapy as a potential pre-TIL therapy strategy in this setting. ${ }^{17}$

\section{Study Limitations}

There are limitations to our study that used a highly aggressive and lethal tumor model in the pleural space. The tumor was not completely eradicated, which may be due to the aggressive nature of the neoplasm and treatment-induced adaptive immune resistance based on PD-1 expression and potential regulatory T-cell upregulation after intrapleural VV-IL-2 administration. ${ }^{41}$ Additionally, antiviral antibody and natural killer cells may lead to premature virotherapy neutralization, which may explain incomplete tumor eradication and nonsignificant differences in tumor infiltration as seen in Figure $3, D$. Despite reduced regulatory $\mathrm{T}$ cells in previously described colon cancer murine models $(4 \%$ of total TIL population in PBS controls to $0.8 \%$ in the VV-IL-2 cohort), ${ }^{17}$ it is worth further exploring this cell subset and corresponding checkpoint receptor expression (CTLA-4, LAG-3, TIM-3, TIGIT, PDL-1) in the present MPD model as we further improve these immunotherapeutic interventions. ${ }^{42}$ Upregulation of immune checkpoint interaction can also promote immunosuppression by enhancing regulatory T-cell function and proliferation within the TME, which may contribute to reduced antitumor immunity despite VV-IL-2 treatment. ${ }^{41}$

There was limited pleural effusion (bloody, $<10 \mu \mathrm{L}$ ) that was poorly reproducible in the MPD tumor model. This is not an uncommon finding in other established murine models of pleural disease. ${ }^{16,17}$ Thus, we believe that pleural carcinomatosis is an acceptable alternative for advanced spread seen in a subset of patients with secondary MPD. The aggressive nature of this MPD model, leading to rapid pleural carcinomatosis and respiratory failure, adds to the significance of the observed median $43 \%$ survival benefit 
and reduction in tumor burden. Use of a luciferase transfected tumor cell line may have elicited an immune response that is noticeable with decreased gross tumor mass but not accounted for during tumor bioluminescent imaging quantification.

\section{CONCLUSIONS}

To date, local control of secondary MPE is largely palliative. Our study represents the first preclinical study that uses intrapleural OV in an MPD murine model. Our findings suggest that VV-IL-2 is an effective IL-2 immunotherapy that should be considered for patients with refractory MPD.

\section{Conflict of Interest Statement}

D.W. and W.P. are employees of iRepertoire, Inc. All other authors reported no conflicts of interest.

The Journal policy requires editors and reviewers to disclose conflicts of interest and to decline handling or reviewing manuscripts for which they may have a conflict of interest. The editors and reviewers of this article have no conflicts of interest.

\section{References}

1. Burrows CM, Mathews WC, Colt HG. Predicting survival in patients with recurrent symptomatic malignant pleural effusions: an assessment of the prognostic values of physiologic, morphologic, and quality of life measures of extent of disease. Chest. 2000;117:73-8.

2. Zamboni MM, da Silva CT Jr, Baretta R, Cunha ET, Cardoso GP. Important prognostic factors for survival in patients with malignant pleural effusion. BMC Pulm Med. 2015;15:29.

3. Murthy P, Ekeke CN, Russell KL, Butler SC, Wang Y, Luketich JD, et al. Making cold malignant pleural effusions hot: driving novel immunotherapies. Oncoimmunology. 2019;8:e1554969.

4. Russell SJ, Peng K-W, Bell JC. Oncolytic virotherapy. Nat Biotechnol. 2012;30: 658-70.

5. Andtbacka RH, Kaufman HL, Collichio F, Amatruda T, Senzer N, Chesney J, et al. Talimogene laherparepvec improves durable response rate in patients with advanced melanoma. J Clin Oncol. 2015;33:2780-8.

6. Rehman H, Silk AW, Kane MP, Kaufman HL. Into the clinic: Talimogene laherparepvec (T-VEC), a first-in-class intratumoral oncolytic viral therapy. J Immunother Cancer. 2016;4:53.

7. Galluzzi L, Vitale I, Warren S, Adjemian S, Agostinis P, Martinez AB, et al. Consensus guidelines for the definition, detection and interpretation of immunogenic cell death. J Immunother Cancer. 2020;8:e000337.

8. Senzer NN, Kaufman HL, Amatruda T, Nemunaitis M, Reid T, Daniels G, et al. Phase II clinical trial of a granulocyte-macrophage colony-stimulating factor-encoding, second-generation oncolytic herpesvirus in patients with unresectable metastatic melanoma. J Clin Oncol. 2009;27:5763-71.

9. Hu JC, Coffin RS, Davis CJ, Graham NJ, Groves N, Guest PJ, et al. A phase I study of OncoVEXGM-CSF, a second-generation oncolytic herpes simplex virus expressing granulocyte macrophage colony-stimulating factor. Clin Cancer Res. 2006;12:6737-47.

10. Boyman O, Sprent J. The role of interleukin-2 during homeostasis and activation of the immune system. Nat Rev Immunol. 2012;12:180-90.

11. Yanagawa H, Haku T, Hiramatsu K, Nokihara H, Takeuchi E, Yano S, et al. Intrapleural instillation of interferon $\gamma$ in patients with malignant pleurisy due to lung cancer. Cancer Immunol Immunother. 1997;45:93-9.

12. Sartori S, Tassinari D, Ceccotti P, Tombesi P, Nielsen I, Trevisani L, et al. Prospective randomized trial of intrapleural bleomycin versus interferon Alfa- $2 \mathrm{~b}$ via ultrasound-guided small-bore chest tube in the palliative treatment of malignant pleural effusions. J Clin Oncol. 2004;22:1228-33.
13. Goey SH, Eggermont AM, Punt CJ, Slingerland R, Gratama JW, Oosterom R et al. Intrapleural administration of interleukin 2 in pleural mesothelioma: a phase I-II study. Br J Cancer. 1995;72:1283-8.

14. Castagneto B, Zai S, Mutti L, Lazzaro A, Ridolfi R, Piccolini E, et al. Palliative and therapeutic activity of $\mathrm{IL}-2$ immunotherapy in unresectable malignant pleural mesothelioma with pleural effusion: results of a phase II study on 31 consecutive patients. Lung Cancer. 2001;31:303-10.

15. Han L, Jiang Q, Yao W, Fu T, Zeng Q. Thoracic injection of low-dose interleukin2 as an adjuvant therapy improves the control of the malignant pleural effusions: a systematic review and meta-analysis base on Chinese patients. BMC Cancer. 2018;18:725.

16. Liu Z, Ge Y, Wang H, Ma C, Feist M, Ju S, et al. Modifying the cancer-immune set point using vaccinia virus expressing re-designed interleukin-2. Nat Commun 2018;9:4682.

17. Feist M, Zhu Z, Dai E, Ma C, Liu Z, Giehl E, et al. Oncolytic virus promotes tumor-reactive infiltrating lymphocytes for adoptive cell therapy. Cancer Gene Ther. July 7, 2020 [Epub ahead of print].

18. Acencio MMP, Puka J, Marchi E, Antonangelo L, Terra RM, Vargas FS, et al. A modified experimental model of malignant pleural disease induced by lung Lewis carcinoma (LLC) cells. J Transl Med. 2015;13:302.

19. Ma X, Sun Y, Wang S, Yang Z, Song Y. Establishment of a malignant pleural effusion mouse model with Lewis lung carcinoma cell lines expressing enhanced green fluorescent protein. Zhongguo Fei Ai Za Zhi. 2012;15:317-23.

20. Turner PV, Brabb T, Pekow C, Vasbinder MA. Administration of substances to laboratory animals: routes of administration and factors to consider. J Am Assoc Lab Anim Sci. 2011;50:600-13.

21. Wang C, Sanders CM, Yang Q, Schroeder HW Jr, Wang E, Babrzadeh F, et al High throughput sequencing reveals a complex pattern of dynamic interrelationships among human T cell subsets. Proc Natl Acad Sci U S A. 2010;107: 1518-23.

22. Yang Y, Wang C, Yang Q, Kantor AB, Chu H, Ghosn EE, et al. Distinct mechanisms define murine B cell lineage immunoglobulin heavy chain $(\mathrm{IgH})$ repertoires. Elife. 2015;4:e09083.

23. Han J, Lotze MT. The adaptome as biomarker for assessing cancer immunity and immunotherapy. Methods Mol Biol. 2020;2055:369-97.

24. Bolotin DA, Poslavsky S, Davydov AN, Frenkel FE, Fanchi L, Zolotareva OI et al. Antigen receptor repertoire profiling from RNA-seq data. Nat Biotechnol. 2017;35:908-11.

25. Bolotin DA, Poslavsky S, Mitrophanov I, Shugay M, Mamedov IZ Putintseva EV, et al. MiXCR: software for comprehensive adaptive immunity profiling. Nat Methods. 2015;12:380-1.

26. Shugay M, Britanova OV, Merzlyak EM, Turchaninova MA, Mamedov IZ, Tuganbaev TR, et al. Towards error-free profiling of immune repertoires. Nat Methods. 2014;11:653-5.

27. Reuben A, Zhang J, Chiou SH, Gittelman RM, Li J, Lee WC, et al. Comprehensive $\mathrm{T}$ cell repertoire characterization of non-small cell lung cancer. Nat Commun. 2020;11:603.

28. Fend L, Yamazaki T, Remy C, Fahrner C, Gantzer M, Nourtier V, et al. Immune checkpoint blockade, immunogenic chemotherapy or IFN-alpha blockade boost the local and abscopal effects of oncolytic virotherapy. Cancer Res. 2017;77: 4146-57.

29. John LB, Howland LJ, Flynn JK, West AC, Devaud C, Duong CP, et al. Oncolytic virus and anti-4-1BB combination therapy elicits strong antitumor immunity against established cancer. Cancer Res. 2012;72:1651-60.

30. Hosoi A, Takeda K, Nagaoka K, Iino T, Matsushita H, Ueha S, et al. Increased diversity with reduced "diversity evenness" of tumor infiltrating T-cells for the successful cancer immunotherapy. Sci Rep. 2018;8:1058.

31. Aoki H, Ueha S, Shichino S, Ogiwara H, Hashimoto SI, Kakimi K, et al. TCR repertoire analysis reveals mobilization of novel CD8(+) T cell clones into the cancer-immunity cycle following anti-CD4 antibody administration. Front Immunol. 2018;9:3185.

32. Tumor-infiltrating lymphocytes help rein in NSCLC. Cancer Discov. 2020;10: OF5.

33. Iankov ID, Msaouel P, Allen C, Federspiel MJ, Bulur PA, Dietz AB, et al. Demonstration of anti-tumor activity of oncolytic measles virus strains in a malignant pleural effusion breast cancer model. Breast Cancer Res Treat. 2010;122: 745-54.

34. Krug LM, Zauderer MG, Adusumili PS, McGee E, Sepkowitz K, Klang M, et al Phase I study of intra-pleural administration of GL-ONC1, an oncolytic vaccinia virus, in patients with malignant pleural effusion. J Clin Oncol. 2015;33:7559.

35. Lotze H. Adaptive immunity and the tumor microenvironment. Cancer Treat Res 2020;180:111-47. 
36. Han J, Duan J, Bai H, Wang Y, Wan R, Wang X, et al. CR repertoire diversity of peripheral PD-1(+)CD8(+) T cells predicts clinical outcomes after immunotherapy in patients with non-small cell lung cancer. Cancer Immunol Res. 2020;8:146-54.

37. Anagnostou V, Forde PM, White JR, Niknafs N, Hruban C, Naidoo J, et al. Dynamics of tumor and immune responses during immune checkpoint blockade in non-small cell lung cancer. Cancer Res. 2019;79:1214-25.

38. Landre T, Des Guetz G, Chouahnia K, Taleb C, Vergnenegre A, Chouaid C. Firstline PD-1/PD-L1 inhibitor plus chemotherapy vs chemotherapy alone for negative or $<1 \%$ PD-L1-expressing metastatic non-small-cell lung cancers. J Cancer Res Clin Oncol. 2020;146:441-8.

39. Mariniello A, Novello S, Scagliotti GV, Ramalingam SS. Double immune checkpoint blockade in advanced NSCLC. Crit Rev Oncol Hematol. 2020;152: 102980.

40. Wang L-CS, Lynn RC, Cheng G, Alexander E, Kapoor V, Moon EK, et al. Treating tumors with a vaccinia virus expressing IFN $\beta$ illustrates the complex relationships between oncolytic ability and immunogenicity. Mol Ther. 2012; 20:736-48.

41. Kim HR, Park HJ, Son J, Lee JG, Chung KY, Cho NH, et al. Tumor microenvironment dictates regulatory $\mathrm{T}$ cell phenotype: upregulated immune checkpoints reinforce suppressive function. J Immunother Cancer. 2019;7:339.

42. Andrews LP, Yano H, Vignali DAA. Inhibitory receptors and ligands beyond PD-1, PD-L1 and CTLA-4: breakthroughs or backups. Nat Immunol. 2019;20: 1425-34.

Key Words: IL-2, immunotherapy, intrapleural therapy, malignant pleural disease, malignant pleural effusion, metastatic lung cancer, oncolytic virotherapy, PD-1, vaccinia virus 


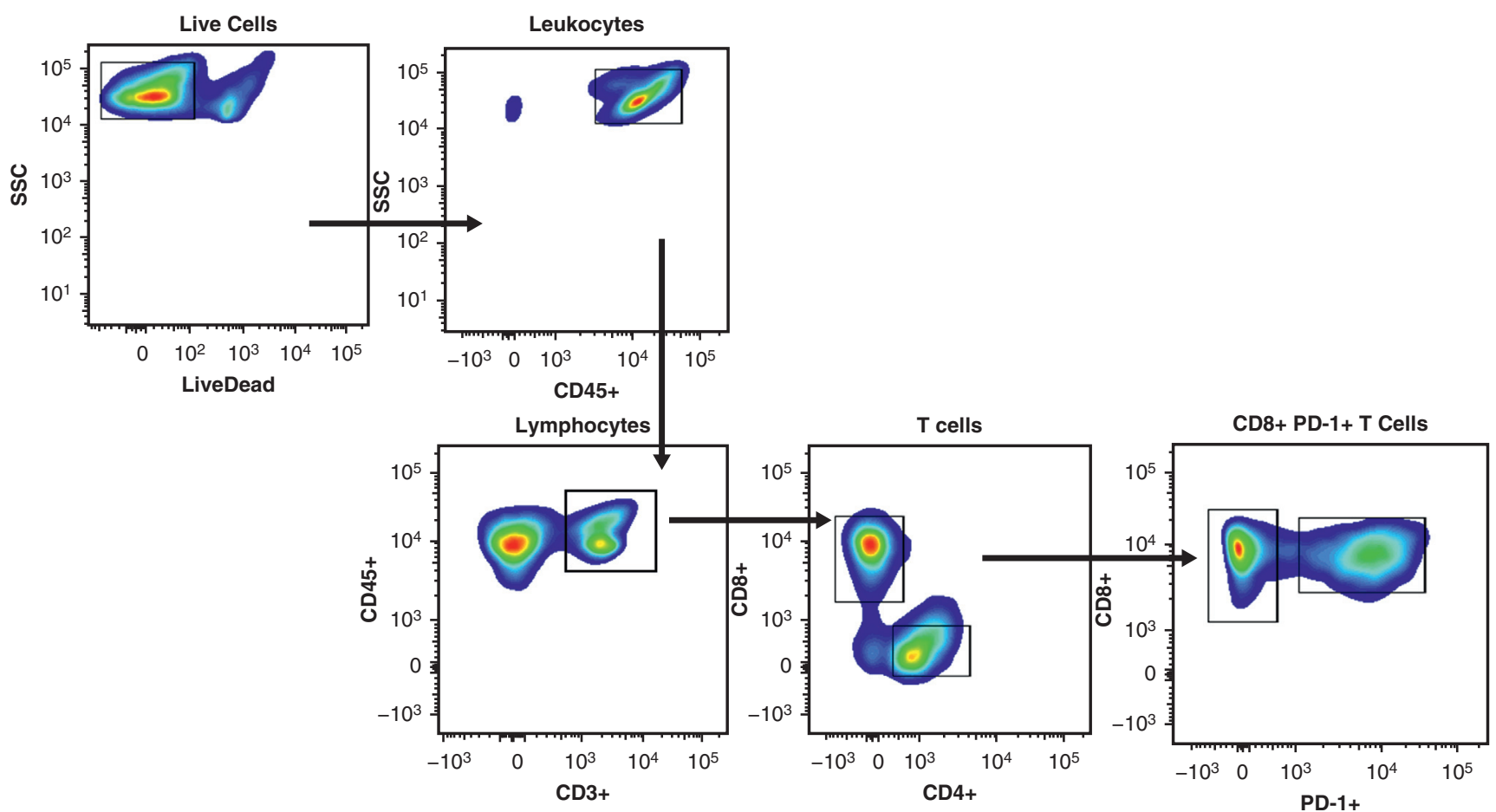

FIGURE E1. Flow cytometric gating strategy. Successive gating strategy used to identify cell types from sized, viable leukocytes, lymphocyte, T-cell subtypes, and programmed cell death protein 1 positivity on $\mathrm{CD} 8^{+} \mathrm{T}$ cells.
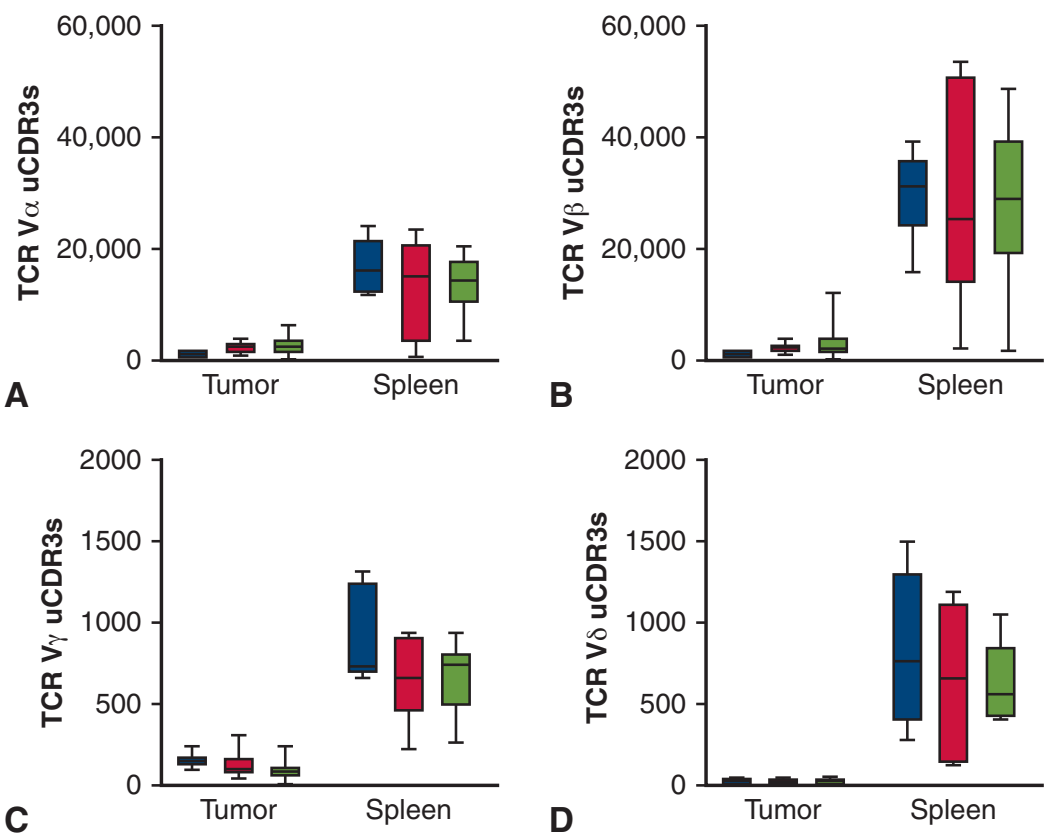

$\square$ aPD-1 $\square(\mathrm{L}) \mathrm{VV}-\mathrm{IL}-2 \square \mathrm{Combo}$

FIGURE E2. Nonsignificant change in intratumoral and splenic CDR3s with VV-IL-2 and combination treatment. Unique CDR3 mRNA expression for V $\alpha$ (A), $\mathrm{V} \beta(\mathrm{B}), \mathrm{V} \gamma(\mathrm{C})$, and $\mathrm{V} \delta(\mathrm{D})$ chains in tumor and spleen from MPD mice treated with systemic anti-PD-1 alone ( $\mathrm{n}=7)$, intrapleural VV-IL-2 alone $(\mathrm{n}=9)$, or combination anti-PD-1 and VV-IL-2 $(n=8)$. 

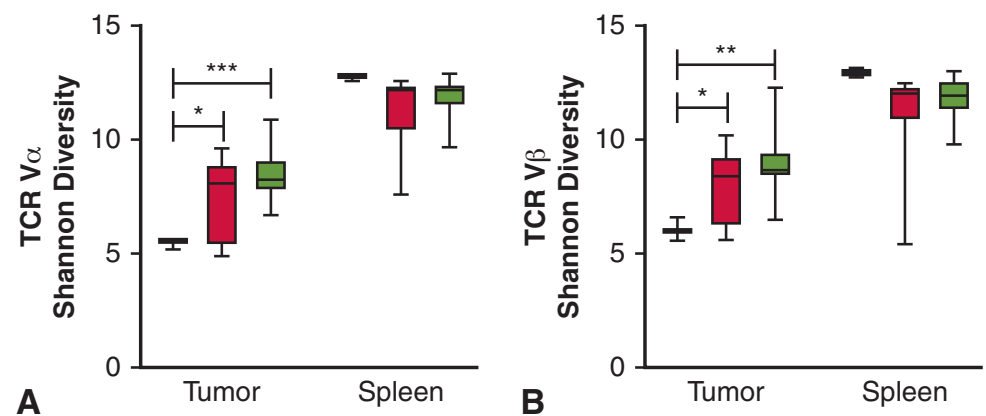

aPD-1

(L) VV-IL-2 $\square$ Combo

FIGURE E3. VV-IL-2 and combination treatment increase TIL Shannon diversity index. V $\alpha$ (A) and V $\beta$ (B) Shannon diversity index were assessed in tumor and spleen from MPD mice treated with systemic anti-PD-1 alone $(\mathrm{n}=7)$, intrapleural VV-IL-2 alone $(\mathrm{n}=9)$, or combination anti-PD-1 and VV-IL-2 $(\mathrm{n}=8) . P$ values are reported $(* P<.05, * * P<.01, * * * P<.001)$. 